\title{
Discussion on Tight Balance Between Money and Credit in Financial Econ Omic Cycle
}

\author{
Xu Xinjie \\ Faculty of Economics and Law, Zhejiang University of Commerce and Industry Hangzhou Business School, Hangzhou, China
}

\section{Email address:}

xuxinjie111@qq.com

\section{To cite this article:}

Xu Xinjie. Discussion on Tight Balance Between Money and Credit in Financial Econ Omic Cycle. Science Innovation.

Vol. 6, No. 4, 2018, pp. 196-200. doi: 10.11648/j.si.20180604.14

Received: June 22, 2018; Accepted: July 12, 2018; Published: July 20, 2018

\begin{abstract}
The economic changes of a country are affected by various factors, and it is of great significance to study the economic cycle to grasp the policy direction of future economic development. Generally speaking, financial changes have a direct and rapid impact on changes in the world economy as a whole. In the melt under the background of the economic cycle, the relationship between "money" and "credit", will help the country to establish a stable monetary policy, and avoid financial risks and credit crisis, to promote the steady development of national economy.
\end{abstract}

Keywords: Financial and Economic Cycles, Money, Credit

\section{金融经济周期中“货币”与 “信用”紧平衡的探讨}

\section{许金桖杰}

经法分院, 浙江工商大学杭州商学院, 杭州, 中国

\section{邮箱}

xuxinjie111@qq.com

摘要：一国的经济形式变化受各种因素的影响, 研究经济周期对于把握未来经济发展的变动方向具有重要的意义。一 般来说，金融的变动对整个世界经济的变化的影响是直接而迅速的。在经融经济周期的背景之下，研究“货币”和“信用” 之间的关系，有助于帮助本国建立稳定的货币政策，避免金融风险和信用危机，从而促进国家经济的稳定发展。

关键词：金融经济周期，货币，信用

\section{1. 引言}

关于金融经济周期的研究，近年来也有了一些比较明 显的成果。孙怀宇、张捷 (2015) 提出货币政策应通过预 先判断信贷市场对政策运作的反应, 选择合理的政策工具, 调整政策的规模和时机, 来提高流动性管理的合理性和稳 健性[1]。赵宁（2016）指出在所有因素中, 金融经济周期 所占据的比例尤为重要。在社会的不断发展中, 对经济发 展的需求越来越高, 新因素直接导致财政对经济的影响不
断改善[2]。杨时革（2016）提到金融改革的主线之一是将 文化内涵和制度因素纳入传统的金融理论模型，传统的金 融理论模型涉及传统的金融问题: 金钱及其来源, 因此在 他的研究中更加关注政治或社会关系对货币, 货币政策和 经济周期的影响[3]。郭晔、黄振、王蕴（2016）认为, 首 先, 未预期的货币政策对公司债券的信用利差影响更大; 第二, 在经济形势比较好的时期, 该政策对公司债券的信 
用利差影响较大; 第三, 货币政策对中长期公司债券信用 利差的影响比同期公司债券的影响更为明显 [4]。何睿哲 （2017）对金融经济周期进行了定义判断，认为该概念是 指金融系统传导功能形成的周期性和持续的经济变化。从 微观角度来看, 其存在基础是金融加速器, 信贷波动和资 产价格波动是该过程中的重要关注点[5]。张捷（2017）认 为在多重目标的平衡中, 政策监管的难度和复杂性有所增 加，在此期间应该警惕货币政策对房地产和金融经济周期 的转折点所造成的影响[6]。实践证明, 在一国经济发展的 任何时期过热或者过冷的经济变化都不利本国经济的持 续健康发展。在经济周期的影响之下，更要注重保持金融 稳定, 为了更好地把握经济周期变动的规律及其影响, 制 定出行之有效的实际策略, 本文提出要能够正确的处理 “货币”与“信用”之间的“紧平衡”关系，从宏观上把握货币 政策的重要意义, 避免经济风险的产生。本文对金融经济 周期中“货币”与“信用”紧平衡进行探讨, 分析其内在的规 律, 并提出几点建设意见。

\section{2. 经济周期背景下的货币扩张}

货币扩张存在于两个方面, 其一是信用扩张, 其二是 非信用扩张。从金融发展史上来看, 随着金融体系的建立 和完善, 金融发展的抑制作用也在不断的加强。尤其是信 贷交易的制约性越来越大, 信用要求也随之提高。早些时 候, 以政府一方主导的货币扩张, 主要是通过财政支出的 方式进行。但是, 财政支出也带来一些弊端, 甚至引发通 货膨胀, 总需求上涨, 但是本国国内的供给却相对不足。 中国在财政支出问题上一直存在着行政支出较多、民生经 营较少的问题。一般来说，行政支出增长与推动经济发展 和社会进步之间有着合理的一面, 但由于支出项目的不断 扩张, 人员的过剩, 资金虽然快速增长但是政府的服务效 率依然低下, 没有达到财政支出的目的, 其增长存在不合 理的一面。中国政府尽管进行了几次大规模的体制改革, 但该方面的问题不断出现反弹, 形成了精简之后又出现膨 胀的恶性循环, 造成各级财政困难程度持续加深。

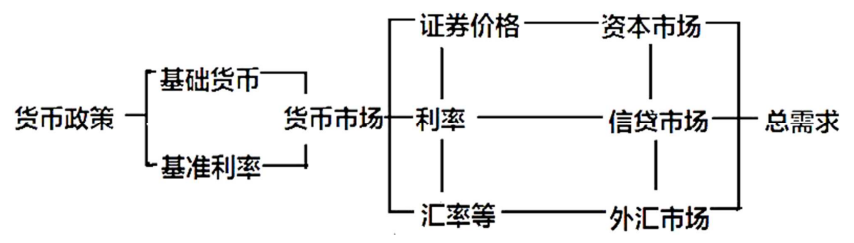

图1 货币政策传导的基本过程。

从2007年底爆发的美国次贷危机是一个重要节点, 经 此转折, 全球经济开始走入低迷时代。对这一时期的经济 运行状况进行深入调查可以发现, 它表现出了非常明显的 经济周期特征, 即信贷扩张和房地产价格波动, 以及受到 内外部冲击的金融和经济活动, 以及通过已经建立起来并 形成了一定机制的金融体系，在此基础上出现了连续的周 期性变化。经济不断发展, 金融交易的方式种类越来越多, 金融业不断发展，金融自由化不断推进，由于金融波动受 市场变化的影响, 所以总体来看已经形成经济周期的变化 规律[7]。从历史发展和数学家经济学家的计算总结来看,
通过“信用”来推动的货币扩张存在两种方式, 首先是货币 乘数扩张, 乘数效应的作用不仅仅体现在货币扩张的方面, 其出现之后影响极深。其次是新增信贷扩张。而非信用推 动的货币扩张同基础货币、外汇占款和财政存款有关。在 此基础之上，对于正确处理“信用”和“货币”之间的关系， 也就是关于“紧信用”还是“稳货币”, 或者“紧货币”还是“稳 信用”, 要根据具体的历史情况进行具体的分析实施 [8]。

\section{3. 经济周期背景下的信用扩张}

奥地利学派经济学家、自由主义思想者Mises的经济 周期理论认为, 如果没有商业银行出现的信用扩张, 经济 周期就不会发生太大的起伏[9]。当经济不断呈现出良好态 势时, 企业方面原有的盈利能力会增加, 相比之下借贷意 愿也会随之增强, 它们需要借助更多的资金来扩大生产, 以此达到巩固市场、提高利润率的目的。在这一点上, 商 业银行往往更愿意扩大信用业务, 银行信贷的增加促进了 企业的生产投资和经济发展。反过来, 经济推动信用扩张, 并形成了良性循环, 同时商业银行的信用扩张促进了经济 的繁荣。但是, 这一现象不会无限期地持续下去。信用扩 张有可能导致通货膨胀, 价格上涨将导致更高的投资成本, 企业方面将会滋生更多的资本需求。如果这种模式在未来 难以继续下去, 那么很有可能爆发金融危机。Mises认为 如果是人为原因导致的低利率, 那么原本无利可图的项目 在这一状况下将会变得更有吸引力, 投资者容易冲昏头脑, 容易犯错, 容易造成过度投资问题。如果现有储蓄没有办 法继续支持这种投资时，这些项目也将无法继续下去。此 时, 投资的积极循环无法实现。在高成本的时期, 投资成 本高的企业家可能会在产品销售、产能过剩等方面出现诸 多损失，巨大的损失也意味着萧条时代的到来。“货币”和 “信用”是相互联系的，相互之间并非对立关系。货币扩张 能够在信用制度的发展下进步, 同样在经济周期的背景下 信用扩张也离不开货币政策的助推作用[10]。2008年之前, 商业银行的资产规模与中央银行的资产相比, 总量上前者 是后者的几倍, 随着时间的推移商业银行的总资产在逐年 的减少。

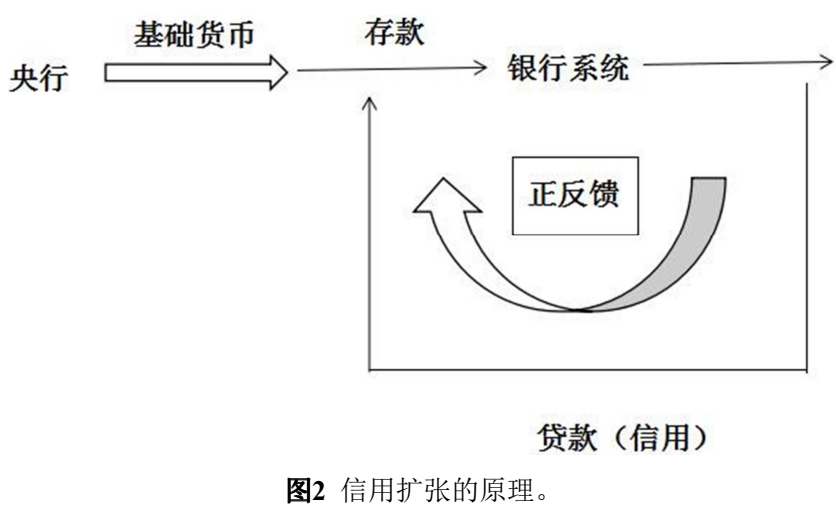

但是2008年之后，商业银行的总资产不仅是中央银 行总资产的几倍, 而且在逐年的增加, 从这一方面可以 看出信用符合周期变动的规律条件之下在不断地扩张。 从增量变动的口径来看, 2008 年的经济危机以来, 社会 
总资金占有量增加，从侧面反映出资金周转的情况。经 济发展越繁荣, 经济周期的波动就越来越强烈, 持续时 间也比以往更长。从社会资金的增量口径上，可以看出 一国信用的发展程度, 所以数据表明, 信用扩张在不断 地加剧, 成周期性的波动。信贷的发展, 反映到社会经 济金融领域，资金在社会生产经营的各个方面流动，资 金的融合性越来越强, 社会总的需求旺盛, 从而看出的 社会经济的发展水平。反过来, 社会资金的流动也会折 射信用扩张的变化。历史发展不是一成不变的, 经济有 低迷期也有繁荣期, 所以整个经济发展会朝着周期变动, 信用扩张也是如此[11]。

\section{4. 两大底线思维}

根据经济周期的变化, 经济发展中存在的各种问题, 信用缺失问题对于金融稳定有极大的负面影响。混乱的信 用以及无秩序的管理必须引起足够的重视，这是防止金融 风险的关键。另外除了信用问题的影响之外, 还存在一些 其他的问题, 比如商业银行的治理问题。信用缺失引发金 融危机和风险, 对整个货币体系产生影响。而对于商业银 行的管理而言, 商业银行是管理货币运营、影响货币在市 场流动的主要金融机构, 所以中央银行必须加强对各地区 的商业银行的管理, 利用相关政策措施防止混乱产生。总 之, 一定要确保经济平稳发展, 不能过热也不能过冷, 过 于极端就容易产生问题。在金融和经济周期的后期阶段, 其核心是控制商业银行信贷衍生品的混乱。只有这样才能 抑制资产价格泡沫，消解部分金融体系风险。在这个过程 中，要注意平衡和把握财务风险和经济风险。当金融和经 济周期相对稳定时, 才能促进经济增长和金融稳定。无论 金融和经济周期是过热还是过冷, 经济增长和金融稳定都
将受到负面影响。波动的加剧通常会伴随着经济增长率的 下降和金融危机的发生, 波动的增加不仅会减慢一个国家 的经济增长速度，而且会导致金融体系的不稳定性大大增 加。所以基于此必须遵守两大思维底线。在经济周期的变 动影响之下, 应该认识到: 一是金融波动不会产生外溢效 应; 二是不引发“债务-通缩”的风险[12]。只有严格遵守这 两大底线, 才能在复杂的市场金融环境之下, 促进经济的 平稳运行与发展。

以房地产为例, 在经济环境发展不错的条件下, 经 济向好, 社会生产力以及市场环境科技发展都在同时朝 着有利方向发展, 这一时期房地产的价格开始上涨, 房 地产价格的上升导致外部融资溢价下降, 银行方面更愿 意将更多的资金贷款给企业或者个人，个人用来购房或 者生产投资，企业用于国内的生产，由此整体环境呈现 出信用体系进一步扩张的局面。但是房地产的价格一旦 出现调整或者持续走低, 金融领域就会发生剧烈的反映, 对市场调节的作用就会凸显, 经济很有可能会持续走低, 对国民经济的发展产生重要的影响。信用扩张周期变动 是三年左右, 而房价周期也是三年左右。总的来说, 房 价变动和信用变动之间具有密切关系, 所以必须予以重 视。有人把这两者变动产生的原因归结为金融加速器机 制。由此可以看出, 房价对于经济变化的调整具有很大 的参考意义 [13]。房地产具有可以用于抵押的特征, 其信 用创造能力也高于一般商品和其他的劳动要素。在经济 发展的过程中，房地产市场可以促进资金变化，同时影 响到货币供应状况。从图3可以看出, 中国的房地产开发 贷款和个人贷款余额从 2004 年到 2016 年之间，不断呈现 出上升态势, 并且二者的增幅都高于 M2 (无其他非标项 目和土地购买项目）。

\begin{tabular}{|c|c|c|c|}
\hline 年份 & $\begin{array}{c}\text { 开发贷款和个人贷款余㲁 } \\
\text { (亿元） }\end{array}$ & H2（亿元） & $\begin{array}{c}\text { 贷款占 } 62 \text { 的比重 } \\
(\mathrm{x})\end{array}$ \\
\hline 2004 & 23800.0 & 254107. 0 & 9 \\
\hline 2005 & 28491.0 & 298755.7 & 10 \\
\hline 2006 & 36800.0 & 345577.9 & 11 \\
\hline 2007 & 48000.0 & 403442.2 & 12 \\
\hline 2008 & 49100.0 & $₫ 75166.6$ & 10 \\
\hline 2009 & 72878.0 & 610224.5 & 12 \\
\hline 2010 & 93325.0 & 725851.8 & 13 \\
\hline 2011 & 106280.0 & 851590.9 & 12 \\
\hline 2012 & 113630.0 & 974148.8 & 12 \\
\hline 2013 & 136000.0 & 1106525.0 & 12 \\
\hline 2014 & 152000.0 & 1228374.8 & 12 \\
\hline 2015 & 1850000 & 1392278.1 & 13 \\
\hline 2016 & 230000.0 & 1550066.7 & 15 \\
\hline
\end{tabular}

图3 中国房地产贷款开发需求占M2的比重。 


\section{5. 流动性供给周期之变与 “货币” 和 “信用” 紧平衡的把握}

\section{1. 货币供给机制的变化}

众所周知, 银行有两大基础业务, 存款业务和贷款业 务。其中贷款业务是银行赚取利润的主要渠道。银行通过 贷款给企业或者个人, 必须准备充足的资金, 在此过程中 资金存储一般属于存款准备金以及库存现金。商业银行受 中央银行的管制, 所以其法定存款准备金以及库存现金是 商业银行主要的资金储备[14]。一旦社会经济发展出现变 化, 经济结构就会发生变动, 经济结构的变化会影响到货 币供给。流动性管理中, 中央银行发挥的作用各有不同, 当中央银行处于被动地位, 一旦一定时期外汇占款增加, 中央银行货币供给的创造机制就会减弱。而当中央银行在 流动性管理业务中处于主动地位, 整个银行的外汇存款减 少，国内的储备资金和贷款业务随之增加。货币供给创造 机制的能力增强, 央行发挥重要的调节作用 [15]。

在潜在经济增长下降和货币信贷紧缩周期的背景下, 货币政策的核心是预防和防范债务危机造成的预期衰退 风险。主要是因为利率上升和资产价格下降等状况的出现 很有可能导致外部融资溢价进一步提升, 商业银行将会有 针对性地缩减信用活动。在这个时候, 如果资产价格泡沫 崩溃, 很有可能会受到金融加速器的影响, 经济方面出现 自发的螺旋加速, 导致严重的长期支出收紧和总产出下降 等问题，货币政策将会面临新的挑战。货币供应体系的调 整实际上主要是依赖于金融体系的调整，而不是单一货币 或金融体系的改革, 而是取决于整体宏观管理体系以及政 策目标的转变。地方债置换主要是围绕着央行的资产负债 表来展开, 并在此过程中探索债务货币化。公债的货币化 有利于“硬资产”和长期财务安排的使用, 有利于调整现有 财务结构, 帮助形成更加合理的机制。但在目前的金融体 系中，只能通过地方政府的“土地财政”来尝试着解决相关 问题，地方财政体制调整难以参与[16]。

\section{2. 结构性短缺下的央行管理模式}

商业银行持有的储备金与中央银行资产的增加密切 相关, 中央银行的储备增加反映了中央银行资产的增加, 包括购买外汇, 向商业银行发行债券, 在公开市场购买 债券, 或购买债券回购协议等等。中央银行的净资产注 入是商业银行储备和资金得以缓冲的来源。在流动性不 足的情况下, 储备（预付）的需求保持不变。当银行出 现准备金需求大于准备金的供给的时候, 有可能会造成 结构性短缺的问题。商业银行的准备金来源于中央银行 的净资产注入, 而准备金的需求来自于商业银行, 供给 来自于中央银行 [17]。在这种不平衡的发展条件下, 中央 银行一般会采取以下的管理模式: 首先通过补足差额的 形式满足商业银行的准备金的需求。值得注意的是, 中 央银行控制商业银行, 避免商业银行超额利用存款准备 金, 减少需求, 补足差额, 在该过程中所涉及到的两种 形式, 其一为满足型, 通过增加对其他提供存贷款业务 的机构的要求, 央行将通过增加准备金和储备金的差额 来满足商业银行对准备金的需求。其二是控制型, 中央
银行减缩业务, 商业银行通过减少缓冲现金和超额准备 金来平衡准备金的需求。

由此可以对央行货币政策的三个层次进行概括: 第一, 紧缩货币。这里的“货币”实际上是指“MB”, 而中央银行 的净资产注入率下降, 但流动性管理仍然符合不平衡储备 需求满足型”。实际融资成本主要体现在无风险利率上行, 核心是货币市场的短期利率上行, 而货币政策三大渠道反 映了这一过程。第二, 紧缩信用。这一阶段的核心是减少 资金周转的金融体系, 特别是金融体系的杜杆。从融资成 本来看, 主要表现为外部融资溢价增加。在这个阶段, 除 了利率渠道外, 信用渠道也开始出现。第三, 货币紧缩。 这一阶段表明, 央行对商业银行有更强的控制力, 外部表 现为更为活跃的流动性管理, 央行对不平衡储备的需求以 及流动性空间的管理更加符合“控制型”。在这个阶段，必 须防范资产价格渠道的可能性风险。中央银行的流动性管 理是针对准备金的结构供求不平衡而制定的管理措施, 一 方面满足商业银行的准备金需求, 另一方面通过中央银行 的手段来条件商业银行对准备金供求差额的补足。但是一 般后者所起的作用更为明显, 是央行调节结构性短缺常用 的手段。中央银行结合两种监管模式一方面对商业银行的 货币资金运行进行控制, 另一方面对结构性短缺的状况进 行调节, 以此令货币供给满足市场需求。总而言之, 央行 所使用到的两种管理模式都有其必要性。

\section{3. 有效地把握、保持货币供给和信用扩张之间的平衡 关系}

针对不同的历史发展阶段和具体的实际情况, 需要 特别注意到以下三个方面的问题：1. 在满足准备金需求 时, 减少货币供给, 换言之需要降低央行净资产注入, 强调利率的调节作用。这一时期实行的是“紧货币”措施。 同时, “紧货币”措施要确保满足两个条件, 首先是在管 理过程中, 央行要保证对市场对货币需求的基本满足, 其次央行要保证“紧货币”的过程不能跨度太大, 保证对 基础货币逐渐偏紧的转换。2.减少资金空转，降低金融 风险, 以此为目的实行“紧信用”措施。该阶段要保证金 融中介和中央银行两者的总资产之比的应该逐渐降低, 加强对市场金融的服务能力和水平，从而为整个金融环 境创造良好的服务氛围。3.中央银行加大对商业银行的 控制力度, 平衡结构性短缺, 满足准备金需求。总的来 说，正确处理“货币”和“信用”之间的联系，就必须发挥 中央银行的调节作用, 中央银行起到监督和管理的责任 和义务, 对金融体系中货币运转和信用服务提供积极有 效的政策监管。

\section{6. 结论}

在金融经济周期的变动中, 要能够正确的处理货币与 信用之间的紧平衡关系, 使金融系统趋于稳定, 营造出良 好的大环境。金融的稳定关系着整个国家经济的发展, 要 有稳定的货币政策和良好的信用体系作为支撑。中国金融 服务业还有很长的一路要走, 同西方国家相比, 金融体系 还不完善, 信用制度的建立还存在一定的隐患, 所以必须 
加大力度进行管理和监督。在整个资金运转过程中，发挥 银行的作用, 特别是中央银行对整个经济走势的调节和控 制，保证良好的金融环境，促进中国金融业的稳定发展。 未来市场参与的趋势将持续下去, 市场将会继续向着紧平 衡的方向发展。当然，在这一过程中，所采取的金融政策 无疑会起到关键作用。

\section{参考文献}

[1] 孙怀宇,张捷.潜在经济增速下降中的债务收缩一一基于金 融加速器的视角 [J]. 湖北大学学报 (哲学社会科学 版),2015,42(1):116-120。

[2] 赵宁. 基于金融经济周期探讨银行信用风险管理问题 [J]. 黑 龙江科学,2016,7(24):154-155。

[3] 杨时革.货币、信用与社会关系一一基于货币本源问题的探 索和反思 [J].当代经济,2016(28):126-128。

[4] 郭晔,黄振,王蕴.未预期货币政策与企业债券信用利差一 基于固浮利差分解的研究 [J].金融研究,2016(6):67-80。

[5] 何睿哲. 有关金融经济周期的论述与分析 [J]. 经贸实 践,2017(16)。

[6] 张捷.从金融经济周期看当前经济小周期繁荣的性质与持 续性 [J].财经智库,2017(5)。

[7] 何德旭,张捷.金融经济周期中"货币"与"信用"紧平衡的探讨 $[J]$.上海金融,2017(9):3-7。
[8] 梁斯.流动性“紧平衡”与货币政策操作——对结构性流动性 短缺操作框架的思考 [J].南方金融,2017(9):18-25。

[9] 罗炳昌.A Study of Hong Kong Real Estate Market Volatility:approach from the Austrian School[D].上海财经大 学,2014。

[10] 傅雄广, 李一鸣. 衰退末期货币紧平衡 [J]. 证券市场周 刊,2013(16)。

[11] 王淑娟,王涛.2012年货币政策维持“紧平衡”[J]. 金融世 界,2014(3):124-124。

[12] 王培伟.流动性进入 “紧平衡”, 降准预期渐升温 [J]. 金融世 界,2015(1):24-24。

[13] 克拉萨维娜,Л.H.). 资本主义国家货币流通与信用[M].中国 金融出版社,1987。

[14] 张捷.从金融经济周期看当前经济小周期繁荣的性质与持 续性[J].财经智库,2017(5)。

[15] 李青原,王红建,容欣.基于经济周期的公司盈余持续性研究来自于中国上市公司的经验证据 [J]. 中国会计与财务研 究,2013(4):129-191。

[16] 张平.货币供给机变化与经济稳定化政策的选择 [J].经济学 动态, 2017(7):26-34。

[17] 潘长春. 经济周期、金融周期与货币政策关联机制的理论分 析与计量研究[D].吉林大学,2017。 